\title{
TICs, LEITURA EM LE E GÊNEROS: DA HABILIDADE À PRÁTICA SOCIAL DOCENTE E DISCENTE NA ESCOLA NÃO-PROFISSIONALIZANTE
}

\author{
Jaime de Souza Júnior/Universidade do Estado do Rio de Janeiro
}

\begin{abstract}
RESUMO: Neste artigo, abordo questões relativas ao processo de ensino-aprendizagem de leitura em Inglês como língua estrangeira (LE), tendo como foco a escola pública secundária nãoprofissionalizante. Em função de o trabalho ter se dado com base em uma pesquisa-ação conduzida, apresentarei a abordagem de ensino em que me fundamentei, relatando e discutindo os resultados de implementação prática. Indico como, nessa abordagem, ficam configurados os processos de planejamento e aplicação da sugestão que apresento através deste artigo, focando-me nos seguintes aspectos: a) a habilidade de leitura em LE; b) as Tecnologias da Informação e Comunicação (TICs) como recurso pedagógico; c) os gêneros como instrumento de ensino da língua estrangeira; d) dinâmicas e práticas docente e discente; d) a produção de atividades de leitura em LE.
\end{abstract}

PALAVRAS-CHAVE: Leitura em LE. Gêneros Textuais. TICs. Letramento (digital). Escola pública não-profissionalizante.

\begin{abstract}
In this paper, I address issues related to the teaching/learning process of reading in English as foreign language (EFL), focusing on Brazilian regular public secondary schools. Once my investigation was based on an action-research process, I intend to present the approach which served as a foundation for this study, reporting its results and, consequently, discussing how the practical implementation of that approach took place. In doing so, I indicate how, regarding the approach I suggest here, the planning and the implementation processes could be viewed, considering the following aspects: a) reading ability in a foreign language; b) Information and Communication Technologies (ICTs) as a pedagogical tool; c) genres as a foreign language teaching-tool; d) teacher and learners' routines and practices; d) production of reading-in-a-foreignlanguage activities.
\end{abstract}

KEYWORDS: Reading in a Foreign Language. Textual Genres. ICTs. (Digital) literacy. Regular Public Schools.

\section{INTRODUÇÃO}

Este estudo dá continuidade ao nosso foco de pesquisa, iniciado com o trabalho Inglês para Leitura - Etapas do Curso, 2009i. Aqui, pretendo, a partir de relatos de uma pesquisa-ação por mim conduzida, apresentar e ilustrar aspectos relativos ao ensino de leitura em língua estrangeira (LE), com foco particular no ensino de Inglês para as escolas públicas secundárias nãoprofissionalizantes. 
Em 1998, com a publicação dos Parâmetros Curriculares Nacionais (PCNs), houve a intenção de dotar os professores de língua estrangeira de uma ferramenta metodológica de referência, no sentido de sugerir a tais profissionais um documento que servisse como parâmetro nacional do processo educativo, sendo função do professor, considerar o contexto cultural no qual está inserido ao ensinar determinada LE, valorizando as características de cada região do Brasil para, através das indicações citadas, enriquecer suas aulas. Concordamos com a perspectiva de Celani (1999), ao defender que os PCNs devam ser vistos como um documento de referência. No entanto, entendemos que não pode ser atribuído àquele documento a possibilidade de funcionar como um 'programa de ensino'.

Usualmente, segundo os PCNs (1998, p. 19), o ensino de LE distanciava-se das outras disciplinas no ambiente escolar, fato que, de acordo com a referida obra, "torna o aprendizado desinteressante e inútil para o aluno”. Na nova concepção de ensino percebida a partir dos PCNs, a LE se mostra em comunicação com as disciplinas ministradas na escola. De acordo com os PCNs, essas diferentes associações podem ser alcançadas através "de processos de ensino-aprendizagem que envolvam o aluno na construção de significados pelo desenvolvimento de, pelo menos, uma habilidade comunicativa” (BRASIL, 1998, p. 19).

Outro documento governamental brasileiro denominado Matriz de Referência de Linguagens, Códigos e suas Tecnologias (BRASIL, 2009), que, a partir do ano de 2010, versa sobre as habilidades e competências a serem verificadas no Exame Nacional do Ensino Médio (ENEM) já sugere (e de certa forma determina, por se tratar de um exame de acesso) que o aluno de LE deva:

\footnotetext{
Conhecer e usar língua(s) estrangeira(s) moderna(s) como instrumento de acesso a informações e a outras culturas e grupos sociais.

H5 - Associar vocábulos e expressões de um texto em LEM ao seu tema.

H6 - Utilizar os conhecimentos da LEM e de seus mecanismos como meio de ampliar as possibilidades de acesso a informações, tecnologias e culturas.

H7 - Relacionar um texto em LEM, as estruturas linguísticas, sua função e seu uso social.

H8 - Reconhecer a importância da produção cultural em LEM como representação da diversidade cultural e linguística (BRASIL, 2009, p. 2).
}

O ENEM é um dos exames mais importantes no país, adotado pela maioria das universidades públicas como porta de acesso ao ensino superior. Assim, a partir das premissas dos PCNs (1998) e da Matriz de Referência de Linguagens, Códigos e suas Tecnologias do ENEM (BRASIL, 2009), configura-se como ação do professor da escola pública não-profissionalizante assumir, de forma ética e responsável, seu papel crítico-reflexivo sobre o que, como e através de que meios e para que deve ensinar a disciplina de LE, considerando-se o referido tipo de escola.

Acrescento que, de um ponto de vista crítico-discursivo (FAIRCLOUGH, 2001), o ensino de LE, considerando-se, aqui, o ensino-aprendizagem da habilidade de leitura, pode ser visto como um instrumento de acesso a uma diversidade de comunidades discursivas (no sentido de Askehave; Swales, 2001). Pode ser visto também como forma de acesso a, e também como recurso para o desempenho de diversas práticas sociais (no sentido de Fairclough, 2001) e práticas locais (no sentido de Pennycook, 2010).

Finalizando, neste artigo, então, discuto sobre o ensino-aprendizagem da habilidade de leitura em LE, tendo como unidade linguístico-discursiva central do currículo os gêneros textuais. As TICs, integradas nesse processo, serão vistas como recurso pedagógico tanto para prover textos

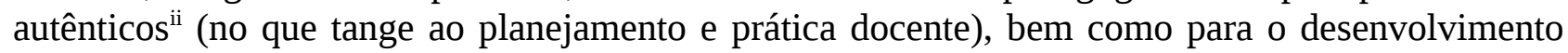


das habilidades de leitura (no que tange às atividades práticas discentes, por meio das quais os alunos interagem e produzem o próprio material, dando formato ao currículo). Por fim, apresento a abordagem de ensino em que me fundamento, seguida de relatos e discussões de seus resultados de implementação prática, indicando como, nessa abordagem, ficam configurados os processos de planejamento e aplicação da sugestão que apresento através deste artigo, focando-me nos seguintes aspectos: a) a habilidade de leitura em LE; b) as TICs como recurso pedagógico ${ }^{\text {iii. }}$ c) os gêneros como instrumento de ensino da língua estrangeira; d) dinâmicas e práticas docente e discente; e) a produção de atividades de leitura em LE.

\section{FUNDAMENTAÇÃO TEÓRICA}

\subsection{Uma abordagem para o ensino de leitura em LE - Língua para Fins Específicos}

A seguir, apresento sucintamente uma descrição do que se entende pela abordagem de ensino de Línguas para Fins Específicos (LFE é, desde 2009, a sigla em português, equivalente à sua antecessora, em Inglês: ESP - English for Specific Purposes), como e quando a mesma se originou. Ademais, procuro discorrer de modo que os processos e procedimentos que integram a referida abordagem sejam conhecidos pelo leitor, tendo como base, principalmente, as visões de Hutchinson e Waters (1987); Robinson (1991) e Dudley-Evans e St. John (1998).

\subsubsection{Características gerais, aspectos essenciais e mitos sobre o ensino de LFE}

Alguns aspectos são considerados essenciais para a caracterização dos cursos de LFE. Dudley-Evans e St. John (1998, p. 5) analisam a relevância da área de ensino de LFE sob a perspectiva de três outros autores e suas definições: em primeiro lugar, segundo os referidos autores (DUDLEY-EVANS; ST. JOHN, 1998, p. 2), Hutchinson e Waters (1987) veem o campo de LFE como uma abordagem em vez de um produto. Em segundo lugar, Dudley-Evans e St. John (1998, p. 3) citam Strevens (1988) e sua distinção entre características absolutas e características variáveis para o ensino de LFE. Essas referidas características vêm para consolidar, segundo os autores (DUDLEY-EVANS; ST. JOHN, 1998, p. 3), a visão de que o campo de LFE remete-nos às referidas características absolutas a seguir: 1) o ensino de LFE é projetado para suprir necessidades especificadas dos alunos; 2) o ensino de LFE é centrado em linguagem apropriada para tais atividades em termos de sintaxe, léxico, discurso, semântica, análise do discurso, etc.; 3) o ensino de LFE está em contraste com a modalidade de ensino tida como Inglês Geraliv (IG) (SOUZA JÚNIOR, 2009, p. 11). As referidas características variáveis em relação à área, de acordo com Strevens (1988), seriam as seguintes: 1) o ensino de LFE pode se restringir à habilidade que o aluno busca aprender (por exemplo, leitura, somente); 2) o ensino de LFE não pode ser ensinado baseando-se em nenhuma metodologia pré-definida.

Robinson (1991, p. 3) afirma que um curso de LFE se baseia em processo de análise de necessidades, visando especificar o mais fielmente possível o que exatamente os alunos têm que fazer enquanto utilizarem a LE. De acordo com Robinson (1991, p. 3), o procedimento de análise de necessidades, há tempos, focava-se muito exclusivamente nos requisitos principais ou naqueles 
requisitos a serem alcançados ao fim de um curso. Atualmente, a autora aponta que é comum levar em consideração as necessidades iniciais dos alunos, incluindo necessidades de aprendizagem. Com relação à linguagem, Dudley-Evans e St. John (1998, p. 4) sugerem que o referido elemento deveria ser incluído como um traço definidor da área de LFE. Um argumento central, segundo DudleyEvans e St. John (1998, p. 4), para que o procedimento de análise de necessidades tenha foco nas atividades, é o fato de estas atividades gerarem e serem dependentes de registros, gêneros e linguagem associada; itens sobre os quais os alunos precisam adquirir conhecimento, a fim de que os mesmos realizem as atividades dos cursos que frequentam.

O ensino de LFE não está pautado em nenhum tipo especial de linguagem. DudleyEvans e St. John (1998, p. 2) afirmam que Hutchinson e Waters (1987) sugerem que uma pista para o surgimento de um enfoque pautado nos princípios da abordagem de LFE se consiga através de uma simples pergunta: "Por que eu preciso aprender uma língua estrangeira?” A resposta para essa pergunta, como afirmam Dudley-Evans e St. John (1998), relaciona-se com os alunos, a linguagem requerida pelo mesmo e o contexto, e, logo, estabelecendo-se, assim, a essência da necessidade no campo de LFE. A partir desses propósitos revelados pela resposta que surgir em relação à referida pergunta, definem-se os pontos de partida, para que, desta maneira, seja determinado o que será ensinado, conforme Dudley-Evans e St. John (1998) nos orientam.

Para finalizar, Robinson (1991) aborda a questão da composição da sala de aula de LFE, indicando que um curso nesses moldes pode ser criado tendo em mente a configuração da aula como um ambiente homogêneo (como nas escolas públicas profissionalizantes brasileiras), isto é, no sentido de que, conforme Robinson (1991, p. 4) aponta, todos os alunos em uma turma estejam envolvidos no mesmo tipo de trabalho ou área de especialização. Em outras partes do mundo, é comum a formação de muitas turmas de LFE mistas (como na escola pública não-profissionalizante, no Brasil).

\subsection{Leitura: atividade humana, cognitiva ou prática social}

Nesta etapa, dirijo-me, mais especificamente, ao leitor menos familiarizado com noções específicas do campo, procurando traçar um panorama acerca dos conceitos do termo leitura. Pretendo também explicitar a concepção de leitura que adotamos neste trabalho, bem como as razões para tal adoção.

De acordo com Silva (2010), “a leitura é uma das atividades humanas mais importantes - se não a mais importante - na sociedade contemporânea”. Ainda segundo Silva, a leitura, no contexto de nossa sociedade caracterizada como pós-moderna e altamente letrada, tem sua construção baseada em práticas de escrita. E essa condição gera exige demandas de refinadas habilidades em leitura e em escrita de todos os membros da referida sociedade.

Silva (2010) lembra que, historicamente, a leitura nem sempre foi vista da mesma maneira. Assim, de acordo com a autora, partimos da compreensão do conceito de "leitura como um processo de oralização da escrita, nos primórdios, quando o homem inventou a escrita alfabética” (ILLICH, 1995; MANGUEL, 1997; OLSON, 1997 apud SILVA, 2010), passando a compreendê-la "como construção de sentidos a partir de toda a subjetividade e historicidade que envolve o homem"(FREIRE, 1994; FOUCAMBERT, 1984; KLEIMAN, 1993, 1995; MANGUEL, 1997; CHARTIER, 1999, 2001, apud SILVA, 2010.) entre outros.

Do ponto de vista cognitivo, conforme Vergnano-Junger (2009), a leitura pode ser vista 
como uma atividade cognitiva marcada por uma gama de procedimentos aos quais recorremos no sentido de construir significados. Acrescenta ainda que, no tocante às diferenças entre Língua Materna (LM) e LE, pode-se dizer que "vários dos procedimentos aprendidos em nossa LM podem ser transferidos à leitura em LE” (VERGNANO-JUNGER, 2009, p. 28). Não separados desses procedimentos e como itens centrais e integrantes do processo de leitura em LE (seja da perspectiva do professor, dos alunos ou dos leitores dessa LE), ainda de acordo com Vergnano-Junger (2009, p. 28) figurarão, assim, "os elementos linguísticos próprios da LE alvo, as especificidades culturais que comporão nossa bagagem enciclopédica sobre os povos que a usam e as novas configurações que os gêneros assumem em suas comunidades linguísticas [...]” (VERGNANO-JUNGER, 2009, p. 28-29). Dessa maneira, ainda de acordo com a autora, o leitor, interagindo através de pistas deixadas pelo autor, se engaja nos seguintes procedimentos: 1) elaboração de hipóteses do que irá encontrar; 2) busca da comprovação ou refutação dessas hipóteses ao longo de sua leitura; 3) inferência do significado das palavras; 4) hierarquização das informações do texto; 5) identificação de ideias pontuais de seu interesse; 6) realização de confronto de informações, à procura de traços de intertextualidade entre o texto atual e textos anteriores; 7) busca de conhecimentos enciclopédicos prévios em sua memória; 8) reflexão sobre as funções coesivas da linguagem. Esses referidos procedimentos, ainda de acordo com a autora (2009, p. 28), têm por objetivo "favorecer a compreensão” (COLOMER e CAMPS, 2000; SILVA, 2001 apud VERGNANO-JUNGER, 2009).

Uma terceira visão a respeito de leitura se coloca. Para Kleiman (1995 apud SILVA, 2010) e Barton e Hamilton (1998 apud SILVA, 2010), o ato de ler é "uma prática social de letramento, entendido como o conjunto de atividades humanas que, de alguma forma, se baseiam na escrita para realizarem-se”. Dessa forma, Silva (2010) concebe a leitura como prática social significativa. Leva em consideração, por esse viés, tanto os seus fatores contextuais quanto suas finalidades. Significa, ainda, a meu ver, ter em conta que a atividade de construção de sentido de um texto em LE não estaria somente a serviço de resultar em sua compreensão estritamente textual, conforme Vergnano-Junger (2009) parece sugerir. Nesse sentido, concordamos também com Freire (1994, p. 11-24 apud SILVA, 2010) quando propõe sua concepção de leitura crítica. A proposta de Freire para a concepção de leitura pode ser vista como um movimento circular entre texto e contexto, buscando, de forma dinâmica, fomentar a (re)compreensão ou (re)escrita do mundo. Conforme Freire (1988) afirmou, "a leitura do mundo precede a leitura da palavra”. Isso traz um novo entendimento sobre mundo, desta vez, de forma mais crítica, pois pode incorporar outros pontos de vista apresentados no texto lido. Nessa perspectiva, aprender a leitura da palavra, tanto em LM quanto em LE, respectivamente, não se limita à memorização mecânica de sílabas e letras ou listas de vocabulário e fórmulas gramaticais, mas se relaciona a práticas sociais significativas para o indivíduo que vive na sociedade letrada.

Em face do exposto, é importante colocar que minha concepção de leitura neste trabalho, engloba as três visões de leitura acima apresentadas, podendo ser classificada como uma visão sociocognitivista (VAN DIJK 2008; VEREZA, 2011). Nesse sentido, o entendimento dessas visões pode ser concebido como uma progressão que parte da condição sócio-histórica e da conscientização do ato de ler, passando pelas relações complexas de uma habilidade cognitiva que é ensinada, aprendida e, principalmente, que pode ser aprimorada tanto em LM quanto em LE, chegando ao nível da prática social - no qual a leitura passa a ser vista mais como um elemento de performance e de produção do que de recepção.

Reconheço também a importância do Modelo Interacional ${ }^{v}$ dentro do escopo deste trabalho, o qual se fundamenta nos modelos de leitura ascendente e descendente.

Por fim, concordamos com Vereza (2011) quando afirma que "uma visão de cognição 
socio-historicamente situada [...] pode nos levar a uma abordagem pedagógica da leitura mais dinâmica e plural, e, portanto, mais eficiente” (VEREZA, 2011, p. 21).

\subsection{O ensino de leitura em LE com base nos gêneros textuais: reconfigurações no currículo}

Nesta seção, pretendo, também, explicitar a concepção de leitura que adotamos neste trabalho, bem como as razões para tal adoção.

A Teoria de Gênero e Registro toma como ponto de partida aquilo se entende por gênero, tendo como base para tal os preceitos da Linguística Sistêmico-funcional. Nesse sentido, conforme Carvalho (2011, p. 51) reporta, um gênero é visto como "atividade com propósito e estágios reconhecidos, na qual os participantes tomam parte ou se engajam como membros de uma cultura” (EGGINS; SLADE, 1997 apud CARVALHO, 2011). Uma definição mais atual e enxuta, de acordo com Carvalho (2011), é a que Martin e White oferecem, definindo um gênero como: "processo social com estágios e propósitos reconhecidos" (MARTIN; WHITE, 2005, p. 32 apud CARVALHO, 2011). Para o analista de gênero e do discurso, conforme Carvalho coloca, torna-se, portanto, possível depreender que: 1) atores sociais produzem os gêneros dentro de seus contextos; 2) gêneros são analisáveis tanto do ponto de vista de sua macroestrutura (aspectos macrodiscursivos) como de sua microestrutura (aspectos microtextuais). Nessa concepção, reconhecer os estágios com base em suas funções e funcionamento, nos leva a entender como o propósito social de um dado gênero é alcançado. Outro aspecto importante a ser apontado por essa concepção de gênero, de acordo com Carvalho (2011, p. 51-52), são as relações semânticodiscursivas dos diferentes estágios e suas realizações léxico-gramaticais

Desta maneira, tomando como base a Teoria de Gênero e Registro, no nível macrodiscursivo, procuro examinar os textos (e fazer com que meu aluno também passe a olhá-lo) como um processo social composto de estágios - de acordo com a especificidade de cada gênero a ser estudado -, tendo cada estágio uma função específica a cumprir, contribuindo, ao mesmo tempo, para a composição do texto como um todo.

Considero também o nível microtextual, onde gêneros apresentam características léxicogramaticais recorrentes, como, por exemplo, em manchetes de jornal (ausência de artigos; verbos no presente); em narrativas (o uso de formas verbais e adverbiais de passado); em manuais de instrução ou receitas (o uso do imperativo e marcadores discursivos de sequência).

Os aspectos apontados pela Teoria em destaque apontam estritamente para o tratamento de análise da composição do gênero; ainda não discorrendo sobre a noção de Registro dentro dessa concepção. Por isso, acho importante lembrar que produzimos textos a partir de nossas interações. Deste modo, concordo com Carvalho quando a autora diz que "o estudo de gênero assim compreendido precisa de ferramentas analíticas que possam dar conta das ações realizadas por meio da linguagem” (CARVALHO, 2011, p. 52). A Linguística Sistêmico-funcional ainda nos oferece suas contribuições nesse sentido, pois compreende a linguagem como "um dentre os sistemas por meio dos quais construímos significado (HALLIDAY, 1985, p. 3 apud CARVALHO, 2011, p. 52), se organizado, de acordo com Halliday (1985, p. 3), "na forma de rede de escolhas léxicogramaticais”.

De acordo com Carvalho (2011, p. 52), essas referidas escolhas léxico-gramaticais são motivadas e não ocorrem no vácuo. Isso se deve ao fato de, nessa concepção, todo uso de linguagem ser visto como pertencente a um contexto. Com base nessa perspectiva, "as 
características textuais permitem que o discurso seja coerente não só com ele mesmo, mas também com seu Contexto de Situação” (HALLIDAY; HASAN, 1985, p. 45 apud CARVALHO, 2011). O Contexto da Situação pode ser entendido como aquele mais imediato da ocorrência de um texto. Dessa forma, como ponto de partida para a descrição do contexto mais imediato de ocorrência de um determinado texto, a Linguística Sistêmico-funcional nos fornece a noção de Registro, que tem como suas variáveis constitutivas os termos Campo, Relações e Modo. Essas variáveis, ainda de acordo com Carvalho, "dizem muito a respeito do que mais imediatamente tem impacto em nossas escolhas lexicais e gramaticais" (CARVALHO, 2011, p. 53). Dessa maneira, quando exponho/reconheço em que área do conhecimento situo aquilo que escrevi/foi escrito e com que propósito comunicativo executo/ foi executada esta ação, estou operando com a variável do Registro denominada Campo. Em segundo lugar, estou operando com a variável do Registro denominada Relações, quando assumo/ reconheço que papel social desempenho/ alguém desempenha textualmente, e se tenho mais ou menos controle sobre meu interlocutor, observando ainda se, nessa relação, há marcas de distanciamento ou proximidade social. Por fim, quando foco minha atenção no papel que a linguagem pode exercer em minhas interações; nos meios e canais (verbal, não-verbal, multimodal, por exemplo) dos quais disponho ao utilizá-la, estou operando com a variável do Registro denominada Modo.

Dessa forma, no processo de ensino-aprendizagem de leitura em LE, com base nos preceitos da Teoria de Gêneros e Registro, permite-se que o aluno aprenda a ler diversos gêneros textuais considerando sua macro e microestrutura, observando também suas variantes de Registro expressas pelo Contexto da Situação.

\section{TICs - recurso pedagógico, meio de acesso a textos em LE e ao letramento digital}

A presença das Tecnologias da Informação e Comunicação (TICs) em nossas vidas é uma realidade cada vez mais incontestável. Talvez, isso se deva ao avanço da divisão de nossas vidas entre as instâncias online e offline, com a primeira dessas ganhando terreno cada vez mais sobre a segunda. Graças ao impulso pervasivo da "necessidade" de se ter a Internet como "companheira” em nosso cotidiano, seja essa necessidade engatilhada pela grande variedade de hardwares (celulares, tablets, laptops etc.) ou de softwares (desde os que prestam serviço, nos avisando onde há engarrafamento na cidade, até os que nos dão acesso às plataformas de jogos ou às redes sociais). Nessa realidade, a Internet, inicialmente vista como um serviço, pode passar rapidamente a ser confundida e ser intrinsecamente requerida, de alguma maneira, como parte integrante do produto (inicialmente eram só hardware + software). Deste modo, o que está configurado para funcionar com base no acesso à Web traz implicações que nos colocam em contato com um grande número de informações (de diversos tipos, extensões, formatos, graus de importância e manifestações de linguagem). Atrelado às nossas rotinas (sejam essas laborais ou não), o acesso a essas informações (por vezes, em diversas línguas) modifica a maneira como nos relacionamos, quando temos contato com estas. De uma perspectiva crítico-discursiva, como Wolton nos diz: “[...] se está diante de um sistema de informação integrado, cuja finalidade está mais para uma economia global do que para um aperfeiçoamento das relações interpessoais [...]" (WOLTON, 2007, p. 102-103).

Assim, só para exemplificar, celulares que têm acesso à Internet, hoje em dia, penso eu, devem ser mais vendidos do que aqueles que não permitem acesso à Web. “Atribuem”, por 
exemplo, status, constituem identidades modernas, refletem quem são as pessoas "antenadas" na sociedade contemporânea. Se a grande maioria dos usuários desses produtos fizesse isso por razões laborais ou de estudo, essa demanda faria certo sentido. Grande parte desses usuários os professores conhecem bem de perto. Estão em nossas salas de aula. Essa minha percepção parece ser corroborada por resultados de uma pesquisa ${ }^{\text {vi }}$ divulgada pelo Instituto Brasileiro de Geografia e Estatística (IBGE) em parceria com a Pesquisa Nacional de Amostragem por Domicílios (PNAD), a qual mostrou que $74 \%$ dos adolescentes entre 15 e 17 anos se conectam frequentemente à Internet.

Neste sentido, a inclusão das TICs como recurso pedagógico no ensino de leitura em LE, em minha concepção e no escopo deste estudo, deve ser vista a partir de dois objetivos críticopedagógicos a serem cumpridos. O primeiro deles é o de possibilitar o acesso a textos autênticos na LE estudada, os quais servirão para desenvolvimento do material didático, essencial ao processo de ensino-aprendizagem das habilidades de leitura em LE, sendo através do material didático gerado e das habilidades de leitura que eles vão requerer para serem lidos que o currículo será constituído. Em segundo lugar, busco promover o letramento digital dos alunos de escolas nãoprofissionalizantes, através do processo de acesso aos textos autênticos que os discentes procurarão na Web - como tarefa de aula. Dessa maneira, aproveitando-me das habilidades que estes já adquiriram, fora da escola, através do uso das TICs como produto, busquei, dentro da escola, mostrá-los que as TICs, como um serviço, também podem ser utilizadas. Isto é, promovendo o desenvolvimento de suas habilidades de leitura na LE estudada, dando acesso a diversos tipos de informação, a diversas comunidades discursivas, possibilitando o exercer de diversas práticas (sociais).

\section{METODOLOGIA E CORPUS}

\subsection{A Análise de Gêneros associada à pesquisa-ação como metodologia}

Nesta etapa, procuro relatar as instâncias de desenvolvimento de uma pesquisa-ação conduzida, procurando discutir alguns aspectos resultantes da aplicação da abordagem de Análise de Gêneros de Ramos (2004), objetivando, assim, embasar a implementação de um curso de dinâmicas e práticas, como sugiro aqui.

Esse estudo ocorreu em uma escola secundária estadual não-profissionalizante, no Estado do Rio de Janeiro, no município de Japeri, Baixada Fluminense, no ano de 2010. Além do pesquisador, três turmas foram envolvidas neste processo: duas do primeiro e uma do terceiro ano do Ensino Médio Regular - em média 80 alunos participantes e três professoras de Língua Portuguesa, que contribuíram, de forma interdisciplinar, como informantes dos alunos acerca de uma pesquisa, solicitada pelo pesquisador, sobre o conceito de gêneros textuais. A escola dispunha de uma sala de informática com oito computadores do tipo desktop, com acesso à Internet de banda larga.

Ramos (2004, p. 116) defende que gêneros textuais são um recurso poderoso para o processo de ensino-aprendizagem, já que, conforme afirmação da autora (2004), aqueles auxiliam o professor de dois modos: a) oferecendo meios de se levantar o que os alunos têm de fazer linguisticamente, ou seja, os discursos que eles precisam ser capazes de compreender na modalidade escrita ou falada; b) capacitando o professor a entender porque um texto é do jeito que 
é, através de considerações sobre seu propósito, seu contexto de situação (sobre o que se fala , o que e com quem se fala e como se fala) e de cultura (HALLIDAY; HASAN, 1985; HALLIDAY, 1985; EGGINS, 1994 apud RAMOS, 2004, p. 116).

Apesar de a proposta de Ramos não ter sido desenvolvida originariamente para implementação nas escolas secundárias não-profissionalizantes da educação básica, defendo que, após alguns ajustes metodológicos, a proposta da autora adquire relevância quanto à sua aplicabilidade também nesse novo segmento educacional. Deste modo, a proposta de Ramos se encontra centrada em duas etapas: 1) planejamento; 2) aplicação.

Ramos (2004, p. 126), afirma que, em sua abordagem, há evidente preocupação em explorar, no decorrer das fases de planejamento e aplicação, a função social, o propósito comunicativo e a relação texto-contexto, visando ao desenvolvimento de um trabalho, que, nascendo das necessidades dos alunos, propicie a realização de atividades socialmente relevantes, utilizando a língua-alvo em uma situação real.

A reflexão a respeito dos processos gerados em cada etapa de implementação desta pesquisa-ação será executada com base nos três processos epistêmicos oriundos da Teoria da Relação com o Saber ${ }^{\mathrm{vii}}$. De forma sucinta, esses referidos processos podem apresentar os seguintes estágios, revelando, cada um, uma relação que os aprendizes desenvolvem no processo de criação de conhecimento, ou seja: 1) objetivação-denominação: o conhecimento como representação e objeto de aprendizagem pelos sujeitos; 2) imbricação do eu na situação: a aprendizagem como um processo de engajamento; 3) distanciação-regularização: o aprendizado pode ser visto como algo que constrói o ser e reflete quem ele é.

\section{$3.2 \quad$ O corpus}

Neste estudo, a partir das etapas de planejamento e aplicação (RAMOS, 2004), os alunos foram envolvidos em diversas dinâmicas e práticas - atividades de pesquisa, de leitura tanto em LM quanto em LE, e produção escrita (em LM) do gênero atividades didáticas de leitura em LE - representando, essas atividades, de forma documental, a sequência das etapas do curso proposto. Desse modo, para cada etapa da metodologia concluída, gerou-se uma atividade representativa dessas. Desta forma, tomo como corpus de análise uma produção significativa desses materiais didáticos de cada uma das referidas etapas (quatro produções no total), uma vez que essas produções estão fundamentadas em todos os aspectos teórico-metodológicos que me guiaram neste estudo.

\section{DISCUSSÃO DOS RESULTADOS}

\subsection{A etapa de planejamento e as atividades geradas}

Considerando-se a etapa de planejamento proposta por Ramos (2004), assumo-a no sentido de preparação prévia dos alunos para lidarem com o conceito de gêneros textuais em um curso de leitura em LE, no âmbito da escola pública secundária não-profissionalizante. 
Nesta etapa, os discentes, trabalhando em duplas, com base nas informações da Figura 1 (abaixo), por solicitação do professor, criaram várias perguntas que acabaram gerando um questionário de compreensão - as perguntas mais adequadas ao desenvolvimento dos conceitos e processos em questão foram escolhidas, pelo professor-pesquisador, para figurarem o questionário final.

Em primeiro lugar, em paralelo ao trabalho de formulação do questionário coletivo sobre gêneros textuais, solicitei que os alunos consultassem mais duas outras fontes de estudo sobre o tema em questão, contrastando-o com o conceito de tipo textual. Nessa concepção, eles teriam que utilizar a Internet como uma das fontes de consulta. Em segundo lugar, deveriam ter seus respectivos professores de Língua Portuguesa como informantes acerca do tema pesquisado promovendo-se, assim, a interdisciplinaridade no escopo da pesquisa, neste momento. Por fim, a tarefa final deveria resultar em um trabalho grupal e escrito, a ser enviado para um e-mail de trabalho, criado pelo professor, no qual constassem as visões sobre gêneros textuais, com base nas fontes pesquisadas, encerrando-se o trabalho com um parágrafo onde os alunos deveriam colocar o que entenderam minimamente sobre 'gêneros textuais'.

\begin{tabular}{|c|c|c|}
\hline Gênero textual & $\begin{array}{l}\text { Partes em que } \\
\text { está dividido? }\end{array}$ & $\begin{array}{l}\text { Propósito } \\
\text { comunicativo? }\end{array}$ \\
\hline $\begin{array}{l}\text { 1-Notícia } \\
\text { (News story) }\end{array}$ & $\begin{array}{l}1^{\mathbf{0}}: \text { Manchete; } \\
2^{\mathbf{0}}: \text { Acontecimentos principais. } \\
3^{\mathbf{0}} \text { : Citação de fala de outras } \\
\text { pessoas. }\end{array}$ & $\begin{array}{l}\text { Informar sobre acontecimentos } \\
\text { considerados importantes para o } \\
\text { público em geral. }\end{array}$ \\
\hline $\begin{array}{l}\text { 2-Relato de Informação } \\
\text { (Information Report) }\end{array}$ & $\begin{array}{l}\mathbf{1}^{\mathbf{0}} \text { : Afirmação geral para } \\
\text { identificar e classificar o assunto; } \\
2^{\mathbf{0}} \text { : Descrição dos destaques. }\end{array}$ & $\begin{array}{l}\text { Descrever e classificar_como as } \\
\text { coisas eram ou são. }\end{array}$ \\
\hline$\frac{\text { 3-Exposição }}{\text { (Exposition) }}$ & $\begin{array}{l}\mathbf{1}^{\mathbf{0}}: \text { Tese (crença); } \\
\mathbf{2}^{\mathbf{o}}: \text { Argumentos; } \\
\mathbf{3}^{\mathbf{o}}: \text { Reforço da tese. }\end{array}$ & $\begin{array}{l}\text { Convencer o leitor, levando em } \\
\text { consideração só } 1 \text { ponto de vista. }\end{array}$ \\
\hline $\begin{array}{l}\text { 4-Resenha Crítica } \\
\text { (Review) }\end{array}$ & $\begin{array}{l}\mathbf{1}^{\mathbf{0}} \text { : Contexto geral; } \\
2^{\mathbf{o}} \text { : Descrição do que está sendo } \\
\text { avaliado; } \\
3^{\mathbf{o}} \text { : Julgamento e avaliação final. }\end{array}$ & $\begin{array}{l}\text { Avaliar produções literárias, de } \\
\text { arte ou de entretenimento. }\end{array}$ \\
\hline$\frac{5-\text { Reconto }}{\text { (Recount) }}$ & $\begin{array}{l}\mathbf{1}^{\mathbf{o}} \text { : Fundamentação; } \\
\mathbf{2}^{\mathbf{o}} \text { : Registro dos acontecimentos; } \\
\mathbf{3}^{\mathbf{0}} \text { : Redirecionamento. }\end{array}$ & $\begin{array}{l}\text { Recontar uma sequência de } \\
\text { acontecimentos. }\end{array}$ \\
\hline $\begin{array}{l}\text { 6-Narrativa (estória) } \\
\text { (Narrative) }\end{array}$ & $\begin{array}{l}1^{\mathbf{0}}: \text { Orientação. } \\
2^{\mathbf{2}}: \text { Complicação. } \\
3^{\mathbf{0}} \text { : Julgamento; } \\
\mathbf{4}^{\mathbf{0}} \text { : Resolução. }\end{array}$ & $\begin{array}{l}\text { Contar uma estória envolvendo } \\
\text { situações problemáticas, com o } \\
\text { sentido de divertir ou instruir. }\end{array}$ \\
\hline$\frac{\text { 7-Explicação }}{\text { (Explanation) }}$ & $\begin{array}{l}\mathbf{1}^{\mathbf{0}}: \text { Afirmação geral; } \\
2^{\mathbf{o}}: \text { Sequência de explicações. }\end{array}$ & $\begin{array}{l}\text { Explicar por que ou como algo } \\
\text { acontece. }\end{array}$ \\
\hline
\end{tabular}




\begin{tabular}{|l|l|l|}
\hline & $\mathbf{1}^{\mathbf{o}}:$ Objetivo principal; & Instruir como fazer algo através \\
\hline 8-Manual & $2^{\mathbf{o}}:$ Etapas; & de uma sequência de etapas \\
\hline (Procedure) & $\mathbf{3}^{\mathbf{o}}:$ Resultado. & \\
\hline
\end{tabular}

Todos os gêneros têm uma forma de manifestação textual. A manifestação textual é o resultado final do texto já acabado. Por exemplo, o gênero 'Reconto' pode ter como sua manifestação textual as Cartas, os E-mails, as Mensagens SMS, os Torpedos de Celular etc.

Uma única manifestação textual pode ser formada por mais de um gênero. Por exemplo, uma carta pode pertencer aos gêneros Relato de Informação, Narrativa e Explicação, ao mesmo tempo.

Figura 1: Atividade de introdução ao planejamento discente [tabela traduzida pelo e adaptada pelo pesquisador, com base em Droga e Humphrey (2002, p. 4)].

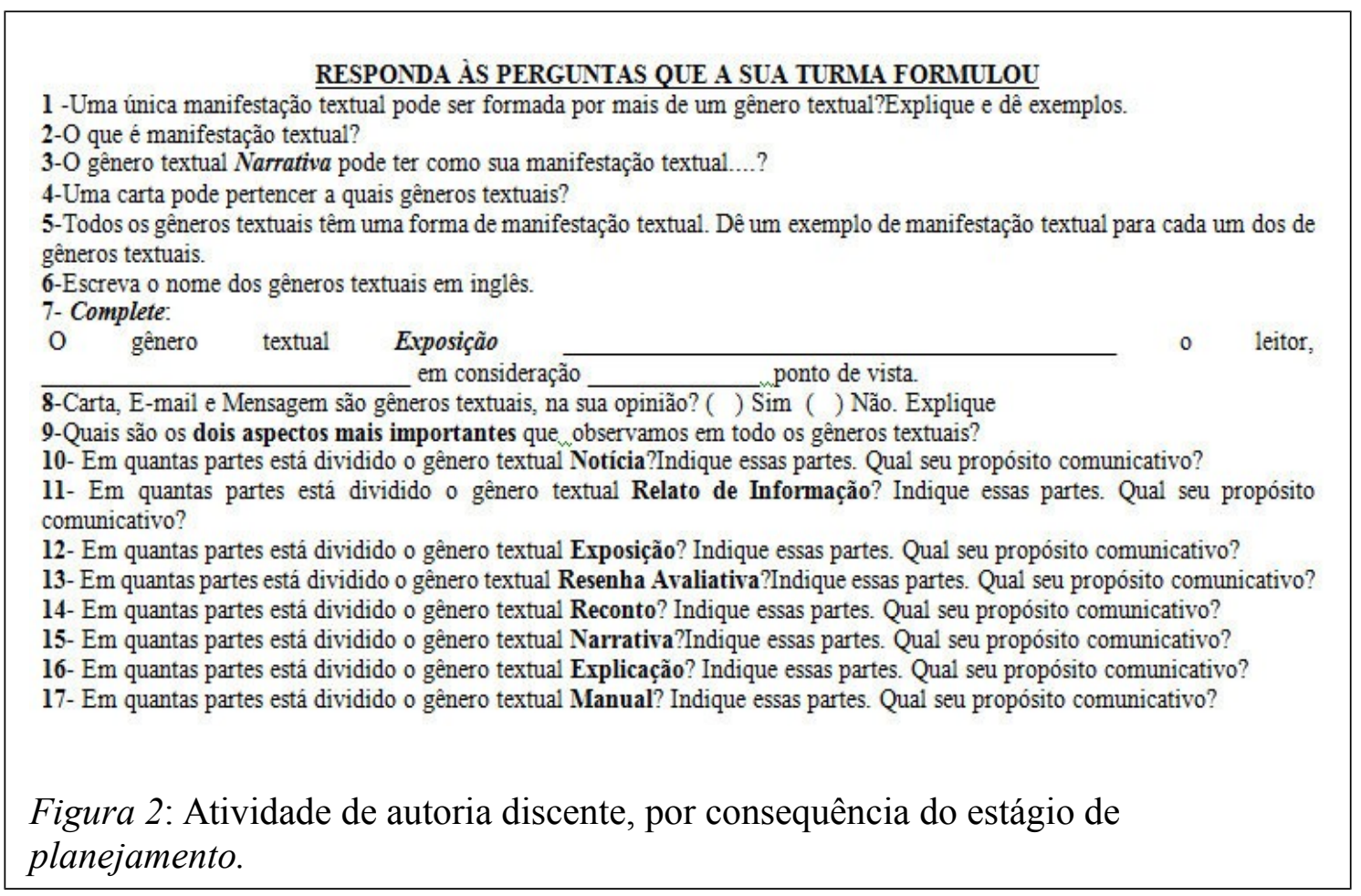

Nesse sentido, e com relação à interpretação dos processos epistêmicos (CHARLOT, 2000) contidos na etapa de planejamento (RAMOS, 2004), houve uma breve introdução acerca dos objetivos de aprendizagem do curso de forma mais representativa, engajada, apesar de ainda pouco tangível, do ponto de vista dos gêneros textuais requeridos e das habilidades de leitura em LE envolvidas no desenvolvimento do currículo do curso na modalidade de ensino em questão. A tangibilidade deve estar atrelada ao estágio de aplicação (RAMOS, 2004), o qual relataremos e discutiremos, a seguir.

Dessa maneira, e com base na Teoria da Relação com o Saber (CHARLOT, 2000), procurei engajar os alunos no processo de ensino-aprendizagem, fazendo com que o resultado de seu engajamento se refletisse em uma produção de conhecimento coletiva oriunda de suas capacidades de leitura (mesmo que ainda em LM) e escrita. Assim, o conceito de gêneros textuais, antes desconhecido, passou a ser visto como saber-objeto. 
Importante notar que, através das atividades descritas na Figura 2, ainda na etapa de planejamento, os alunos já puderam estar em contato com o conceito de gêneros textuais, mesmo que as atividades propostas tenham sido realizadas em LM, no sentido de que, através dessas atividades, os alunos produziram dois gêneros: o primeiro foi o gênero atividade didática em LM (configurado através da produção do questionário coletivo); o segundo foi o gênero relatório de pesquisa bibliográfica; sendo possível, inclusive, associar o uso das TICs como serviço/recurso na realização dessa atividade - uma vez que muitos alunos relataram nunca terem enviado e-mails, apesar de terem um endereço eletrônico, pelo fato de a maioria ter tido necessidade de criar tais endereços para cadastrarem-se nas redes sociais das quais são integrantes e participantes assíduos.

\subsection{A etapa de aplicação, suas subfases e as atividades geradas}

A etapa de aplicação de Ramos (2004) pode apresentar-se divida em três subfases ${ }^{\text {viii }}$, são elas: 1) apresentação; 2) detalhamento; 3) aplicação. Das três subfases sugeridas por Ramos, informo que, na pesquisa em questão, adentrei a fase de aplicação de maneira diversa daquela que Ramos sugere. Dessa forma, o gênero textual, estudado no nível da leitura em LE, funcionou de pretexto para a produção, no nível da escrita em LM, de um segundo gênero: a atividade didática de leitura em $L E$.

O Quadro 1, abaixo, explicita, de maneira sucinta, os objetivos previstos para cada subfase da etapa de aplicação:

\begin{tabular}{|lll|}
\hline 1- Apresentação: & 2- Detalhamento: & 3. Aplicação: \\
Contextualização & $\begin{array}{l}\text { Contato com e análise da } \\
\text { organização retórica }\end{array}$ & $\begin{array}{l}\text { Consolidação } \\
\text { Familiarização }\end{array}$ \\
& $\begin{array}{l}\text { Contato com e análise da léxico- } \\
\text { gramática dos textos }\end{array}$ & Apropriação \\
\hline
\end{tabular}

Quadro 1: Subfases e propósitos da etapa de aplicação (Quadro adaptado de Souza Júnior, 2009, p. 34)

\subsubsection{A subfase de apresentação e as atividades de contextualização e familiarização}

Após a realização da etapa de planejamento, e vislumbrando a implementação da proposta com foco nas três subfases já mencionadas, expliquei aos alunos, em seguida, como a questão da seleção dos gêneros textuais se daria (por vezes, para fins didáticos, utilizei o termo manifestação textual, para evitar incompreensões ou comparações inadequadas entre o tipo de produção textual final e sua possível relação com os termos tipo/tipologia textual e gênero textual, os quais, em termos teóricos, são, sabidamente, mais amplos).

Destacando a introdução das TICs como serviço/recurso na fase de aplicação, revelei que os discentes seriam levados à sala de informática, para que eles selecionassem os textos que comporiam o corpo de materiais didáticos e, consequentemente, a programação de estudo dos quatro bimestres letivos. Acrescentei que essa seleção não se daria de forma aleatória. Eles precisariam das leituras feitas e dos conhecimentos acerca da atividade de acessar a Internet, estando na sala de informática da escola, sob a supervisão do professor, para selecionar textos na 
LE de estudo. Esclareci que esses textos deveriam apresentar algumas estruturações específicas, bem como propósitos comunicativos combinados àquelas estruturas.

Ao apresentar aos alunos a atividade de familiarização e conscientização, conforme a Figura 3, com um texto na língua alemã (sobre a qual nenhum deles detinha conhecimento prévio até a ocasião da Copa do Mundo de Futebol da Alemanha, que ocorria no mesmo ano, naquele país), busquei, conforme Ramos (2004), propor uma conscientização que evoca a sensibilização e tomada de consciência, na medida em que, assim, evidencia aspectos do Contexto de Situação e de Cultura, por exemplo: onde o gênero circula, quem são seus usuários (seu produtor e sua audiência), os porquês de aí circular. Já através do conceito de familiarização, procurei propor, através das perguntas da atividade, a identificação do conhecimento que os alunos já tinham do gênero em questão. Essas perguntas foram criadas no sentido de prover acesso às informações necessárias, bem como dar acesso a informações sobre as quais eles ainda não possuíam sobre os gêneros em questão (considerei igualmente importantes os gêneros tabela informativa, bem como o gênero atividade didática de leitura em LE).

No tocante à composição do gênero atividade didática de leitura em LE, comentei sobre os tipos de pergunta feitos, alertando-os, através da prática, sobre as tão conhecidas estratégias de leitura, tais como: antecipação; previsão; procura por palavras cognatas, repetidas; skimming; scanning.

Dessa maneira, o professor apresentou aos alunos, por conta da subfase de contextualização e familiarização, a seguinte atividade didática, conforme Figura 3, abaixo:

Sie sind hier > Südafrika / WM 2010 Tabelle / WM 2010 Gruppe G

WM 2010 Gruppe G

Finden Sie hier alle Informationen zur WM 2010 Gruppe G. Klicken Sie auf die Links in den Tabellen für weitere Informationen.

\begin{tabular}{|l|l|l|l|l|}
\hline Platz & Land & Spiele & Tore & Punkte \\
\hline 1 & Brasilien & & & \\
\hline 2 & 0 Nordkorea & & & \\
\hline 3 & Elfenbeinküste & & & \\
\hline 4 & Portugal & & & \\
\hline
\end{tabular}

Der Spielplan der Gruppe F. Den kompletten WM 2010 Spielplan anschauen können Sie auch.

\begin{tabular}{|c|c|c|c|c|c|}
\hline Spiel & Datum & Spielort & & Ergebnis & \\
\hline 13 & $\begin{array}{l}\text { 15.Juni } \\
2009\end{array}$ & Port Elisabeth & 1 Elfenbeinküste & & Portugal \\
\hline 14 & $\begin{array}{l}\text { 15.Juni } \\
2009\end{array}$ & Johannesburg / Soccer City & Brasilien & & -Nordkorea \\
\hline 29 & $\begin{array}{l}20 . J u n i \\
2009\end{array}$ & $\begin{array}{l}\text { Johannesburg Ellis-Park- } \\
\text { Stadion }\end{array}$ & Brasilien & & Elfenbeinküste \\
\hline 30 & $\begin{array}{l}21 . J u n i \\
2009\end{array}$ & Kapstadt & Portugal & & Nordkorea \\
\hline 45 & 25.Juni & Durban & Portugal & & Brasilien \\
\hline
\end{tabular}


http://periodicos.letras.ufmg.br/index.php/textolivre

Ano: 2013 - Volume: 6 - Número: 2

\begin{tabular}{|c|c|c|c|c|}
\hline Spiel & $\overline{\text { Datum }}$ & Spielort & \multicolumn{2}{|c|}{\begin{tabular}{|l|} 
Ergebnis \\
\end{tabular}} \\
\hline & 2009 & & & \\
\hline 46 & $\begin{array}{l}\text { 25.Juni } \\
\text { 2009 }\end{array}$ & Nelspruit & - Nordkorea & 1 Elfenbeinküste \\
\hline
\end{tabular}

Hier finden Sie Informationen zu den anderen WM 2010 Gruppen:

(Retrieved from: http://www.southafrika2010.de/wm-2010-tabelle/wm-2010-gruppe-g/)

\section{ATIVIDADE DE CONSCIENTIZAÇÃO- DESAFIO DE LEITURA!!!}

Explore o texto acima e tente responder às questões a seguir:

1- Em qual idioma este texto estaria escrito?

2- Qual a provável função das bandeiras integrarem as tabelas acima?

3- O texto acima parece ter sido retirado de que seção? Justifique sua resposta.

4- O numeral '2010' aparece repetidamente por quê?

5- Na $2^{\mathrm{a}}$ tabela, o que poderiam significar as palavras: "Spiel /Datum/ Spielort/ Ergebnis"?

6-Tente traduzir: "Klicken Sie auf die Links in den Tabellen für weitere Informationen".

7- Apesar de, provavelmente, você não ter estudado o idioma em que o texto está escrito, você

conseguiu identificar muitas das informações que se encontram nele. Por quê? Comente.

Figura 3: Atividade de conscientização e familiarização (Texto em língua alemã).

Assim, com a conclusão desta atividade de conscientização e familiarização, e consequente preparação desses alunos para a etapa futura, os discentes foram levados para a sala de informática, para que eles, tomando por base as etapas até aqui explicitadas, acessassem a Internet e, em duplas, escolhessem, com base nos gêneros apresentados na Figura 1, um texto na LE de estudo. Sendo assim, diferentemente de Ramos (2004), avancei da etapa de apresentação direto para a etapa de aplicação, uma vez que os alunos em questão produziriam, ao nível da escrita, em LM, o gênero atividade didática de leitura em LE, como veremos na próxima subfase: aplicação.

\subsubsection{A subfase de aplicação e as atividades de consolidação e apropriação}

Uma vez que já tinham sido expostos ao gênero atividade didática de leitura em LE, na etapa de consolidação e apropriação, os discentes deveriam, através do uso das TICs como serviço, escolher um dos gêneros constantes da Figura 1, ler o texto escolhido, reconhecendo-o como pertencente ao gênero que escolheu; e elaborando cinco perguntas, conforme exposto na Figura 4, abaixo: 


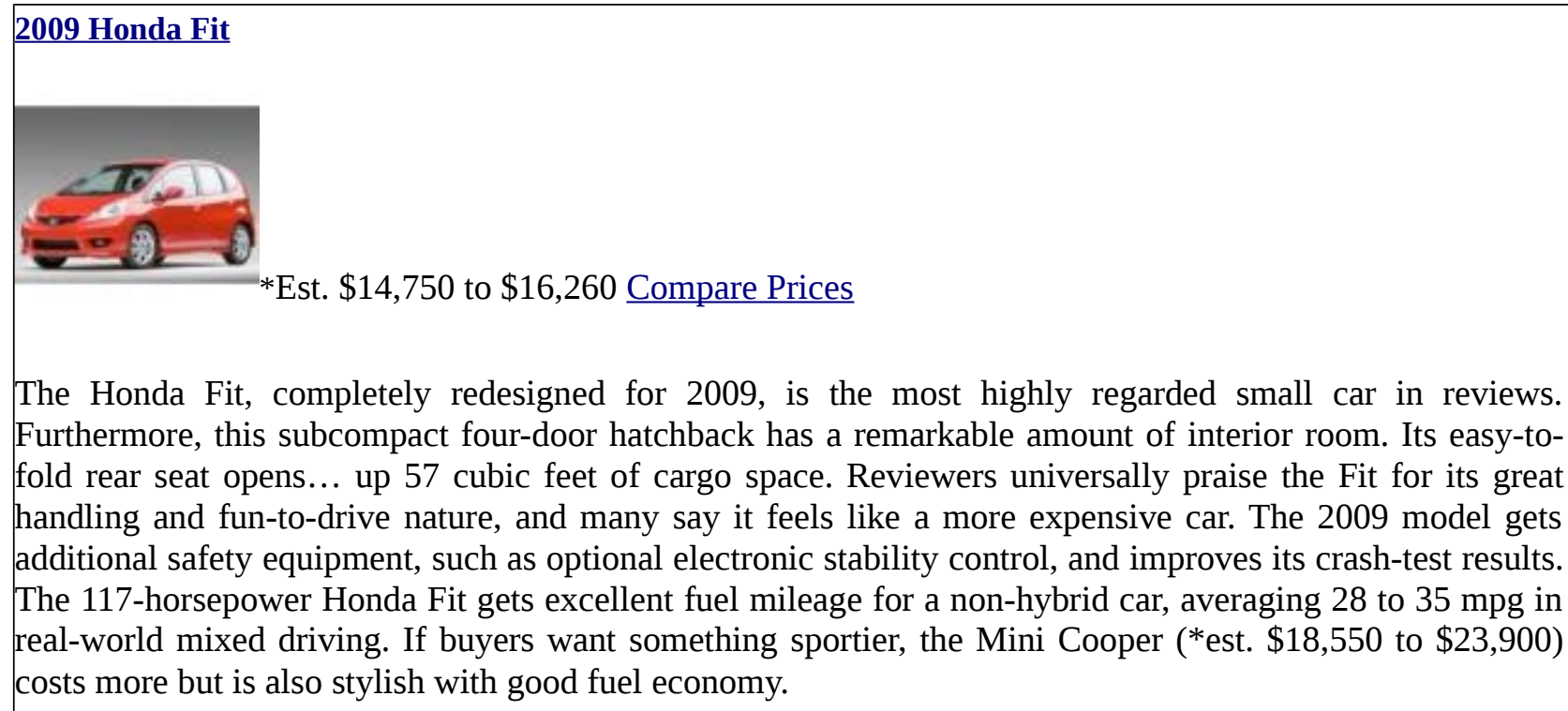

See more photos, specs, and reviews.......

\section{Honda Civic}

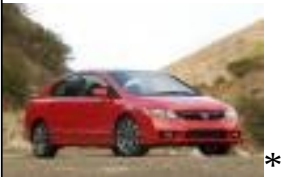

*Est. \$15,305 to \$25,190 Compare Prices

The Honda Civic gets consistently excellent reviews for interior comfort, ride quality, fuel economy, standard safety features, overall long-term reliability and owner satisfaction. The Civic is available as a coupe,... sedan, natural-gas-powered or gas-electric hybrid car (see our separate report on hybrid cars). All Civics come standard with six airbags and antilock brakes. The more powerful (but more expensive), sporttuned Honda Civic Si is especially admired among reviewers; many sources affectionately label it a budget sports car. Real-world fuel economy for the Honda Civic EX is about $26 \mathrm{mpg}$ in mixed driving. A roomy yet still economical alternative within this class can be found in the Nissan Versa (*est. \$9,990 to \$16,330).

See more photos, specs, and reviews.

Acessado em 25/03/10: http://www.consumersearch.com/economy-cars

1- Quanto custa o carro Honda Fit 2009?

2- O que significaria “Compare Prices”?

3- O Honda Civic é considerado excelente em que aspecto?

4- Em que ano a Honda lançou o equipamento adicional para o Honda Fit?

5- Que equipamento foi esse?

Figura 4: Atividade de apropriação e consolidação do gênero atividade didática de leitura em LE.

Após a criação das cinco perguntas (em LM) que estivessem baseadas, mas não restritas às estratégias de leitura mencionadas no parágrafo anterior, e em consonância com os propósitos das perguntas apresentadas na Figura 3, a dupla de alunos deveria checar se as perguntas estavam corretas e/ou apropriadas para o nível de seus colegas. Dessa maneira, o pesquisador pedia que cada 
dupla, após selecionar na Internet o gênero e o texto escolhido, colocasse também o gabarito das questões que elaboraram. O uso do dicionário online só foi permitido para que os alunos executassem de forma mais eficiente sua busca linguística. Assim, por exemplo, se um discente quisesse escolher o gênero textual Receita para criar uma atividade didática na LE de estudo, eles poderiam perguntar ao pesquisador, mas não se manterem dependentes deste. O pesquisador, por sua vez, partindo de uma perspectiva sociointeracionista (VYGOTSKY, 1998), indicava sempre duas possibilidades: “- Procurem no buscador, 'receita em inglês' ou abram o tradutor do buscador, do Português para Inglês, e digitem 'receita'."

Como última etapa da atividade, fazendo uso e explorando os recursos de um processador de texto, observando, inclusive, os erros de Língua Portuguesa, os quais eram indicados em vermelho pelo programa, os alunos deveriam enviar o trabalho formatado e organizado, acessando suas contas de e-mail - aqueles que não dispunham de uma, foram incentivados a criá-la. Dessa maneira, e na condição de monitorador, promovi mais uma oportunidade efetiva para o letramento digital desses alunos, a partir da qual a utilização das TICs como recurso/serviço e não como um produto se tornou possível.

A interpretação das dinâmicas e práticas dessas atividades, de uma perspectiva da Teoria da Relação com o Saber (CHARLOT, 2000), no que tange às ações desses alunos e dos conhecimentos que esses já tinham ou que necessitaram adquirir e demonstrar saber para construir o que construíram se reflete nos eixos epistêmicos da objetivação-denominação, onde o conhecimento sobre a LE, gêneros textuais, estratégias de leitura e TICs mostraram-se claramente refletidos através de cada atividade didática de leitura em LE criada por esses sujeitos. Essas atividades foram tomadas ao mesmo tempo como representação e objeto de aprendizagem pelos sujeitos, gerando, por sua vez, a imbricação do eu na situação, fazendo com que o processo de ensino-aprendizagem aqui relatado tomasse forma através de uma sistemática de dinâmicas e práticas sociais.

No que tange ao papel docente, o resultado dessas dinâmicas e seu montante de atividades didáticas de leitura em LE geradas apontaram para a necessidade de eu reexaminá-las, no sentido de ver qual era a natureza do material que, naquele momento, eu tinha em mãos para compor o currículo de um curso de leitura em LE na escola pública secundária nãoprofissionalizante.

Em face do exposto, analisei quais foram os gêneros mais frequentemente selecionados e quais não foram, sendo necessário incluir no currículo, então, os gêneros textuais indiretamente excluídos pelos alunos. Os gêneros textuais mais frequentemente escolhidos pelos alunos (tanto os do $1^{\circ}$ quanto os do $3^{\circ}$ ano) foram, respectivamente: o reconto (sobre a vida de celebridades), a receita, a letra de música e a resenha crítica.

Analisei também como, por meio de suas habilidades e práticas de leitura, os alunos exploraram esses textos. Desta maneira, verifiquei os tipos de pergunta feitos, observando em quais tipos de estratégias de leitura elas mais frequentemente baseavam-se - o nível de complexidade dessas estratégias -, isto é, se estavam dispostas, do menor para o maior nível de complexidade sociocognitiva: do padrão de compreensão textual para o de interpretação textual, e o de interpretação crítica, respectivamente. As estratégias mais comumente aplicadas pelos discentes no processo de criação de perguntas foram respectivamente: skimming, procura por palavras cognatas e scanning. Quanto ao nível de complexidade sociocognitiva de leitura, todas as perguntas se situaram no nível da compreensão textual. As ausências de escolha indiretamente reveladas também foram tomadas como itens a serem incluídos no currículo do curso e expressas no novo tratamento 
pedagógico pelo qual os materiais produzidos tiveram que ser submetidos pelo pesquisador.

Por fim, perguntas com foco explícito nos aspectos constitutivos dos gêneros textuais (estágios e propósitos comunicativos), Registro (Campo, Modo e Relações) e escolhas léxicogramaticais não integraram nenhuma atividade. Sendo, então, tarefa do professor incrementar as mesmas atividades com questionamentos que contemplassem tais aspectos. Esse procedimento ficou vinculado à subfase de detalhamento, a qual relato e discuto a seguir.

\subsubsection{A subfase de detalhamento: foco nos arranjos retórico e léxico-gramatical}

Para operar na subfase de detalhamento, agora já em sala de aula e com os textos impressos, levando em consideração as exclusões indiretas de diversas naturezas, realizadas pelos alunos, como apontado na seção anterior, decidi manter em primeiro plano o desenvolvimento das habilidades de leitura em LE dos discentes como necessidade primária, considerando, consequentemente, mas não com menor relevância, os conhecimentos sobre a organização retórica dos textos, bem como aqueles sobre as escolhas lexicais que estes textos traziam.

Procurando oferecer um modo de sistematização para suprir essa necessidade dos alunos, implementei, então, no processo de análise dos textos impressos, o formulário apresentado na Figura 5, abaixo, para auxiliá-los.

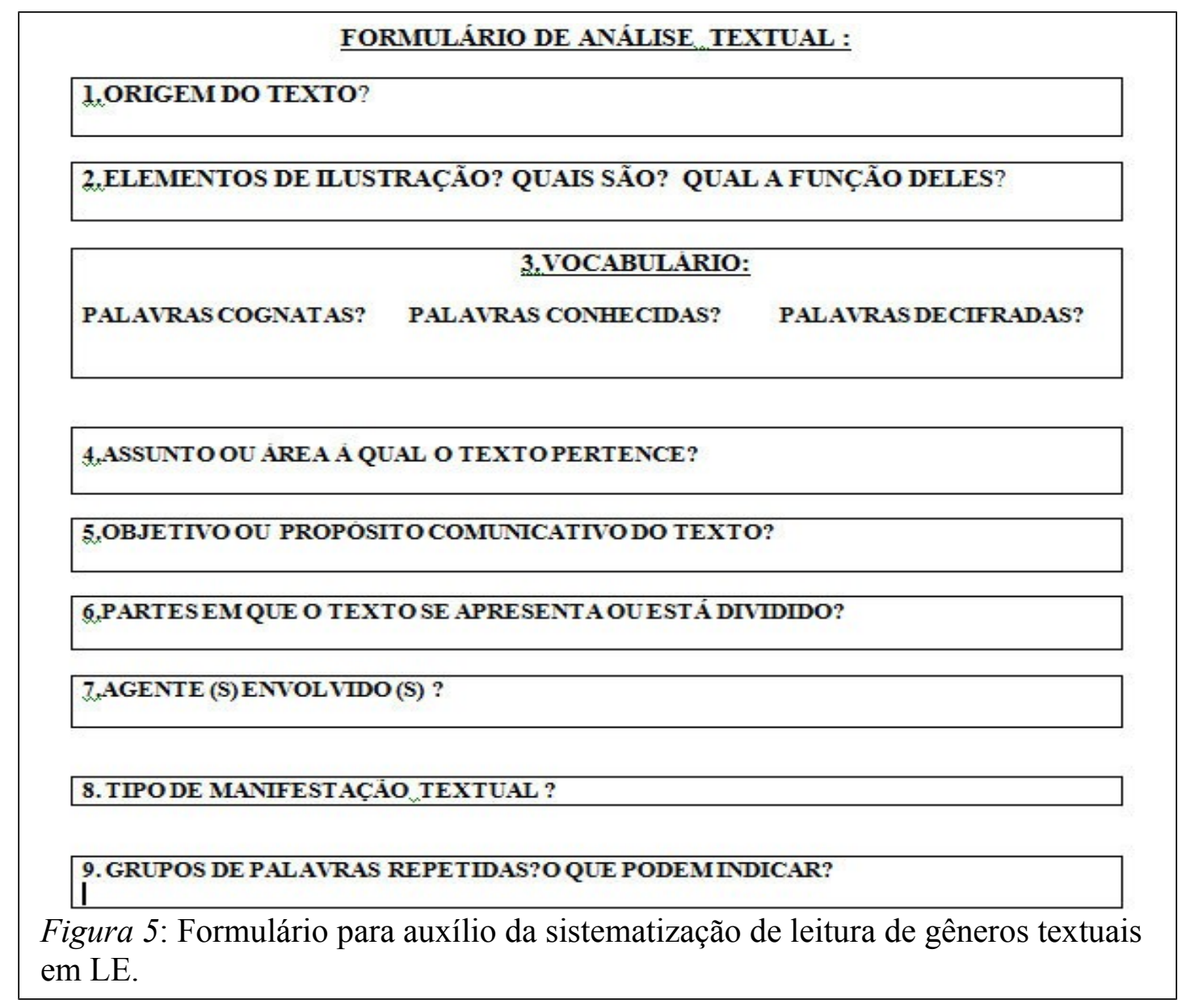


A disposição de cada um dos nove campos constantes da Figura 5 foi pensada considerando-se conjuntamente o processo descendente de leitura (top-down) e o ascendente também (bottom-up) - o que se entende por modelo interacional de leitura (MOITA LOPES, 1996) - nessa perspectiva, é desejável que o aluno comece de um nível mais superficial de leitura para chegar a outro mais aprofundado. Enquanto o processo de leitura descendente pode situar o aluno no estágio de compreensão do texto em LE, a integração dos dois processos possibilita que o discente avance, a partir do processo de compreensão, para os estágios de organização dos textos, analisando por fim e, toda vez que necessário, as escolhas lexicais que têm influência na composição retórica e ideológica desses textos.

Dessa forma, para cada um dos três anos de escolaridade, foi criado um nível de leitura tomando por base os nove campos da Figura 5. Desse modo, ao fim do primeiro ano, os alunos deveriam necessariamente apresentar habilidades de leitura em LE compatíveis com o estágio de compreensão textual, realizando análises que começavam no campo 1 e terminavam no campo 5 do formulário. Por seu turno, alunos do segundo ano deveriam avançar até o campo 7, respondendo a questões de interpretação textual. Por fim, os do terceiro ano deveriam ser capazes de analisar todos os campos, respondendo a questões de interpretação crítica.

Esse avanço, com base nos processos de leitura, procurou ser incentivado pelo pesquisador. Nesta última etapa da pesquisa, o professor acrescentou, por conseguinte, novas questões e reformatou as atividades didáticas de leitura em LE inicialmente geradas pelos alunos sem excluir as questões dos estudantes, no entanto -, para fins de cumprimento dos propósitos da subfase de detalhamento de Ramos (2004), conforme Figura 6, a seguir: 


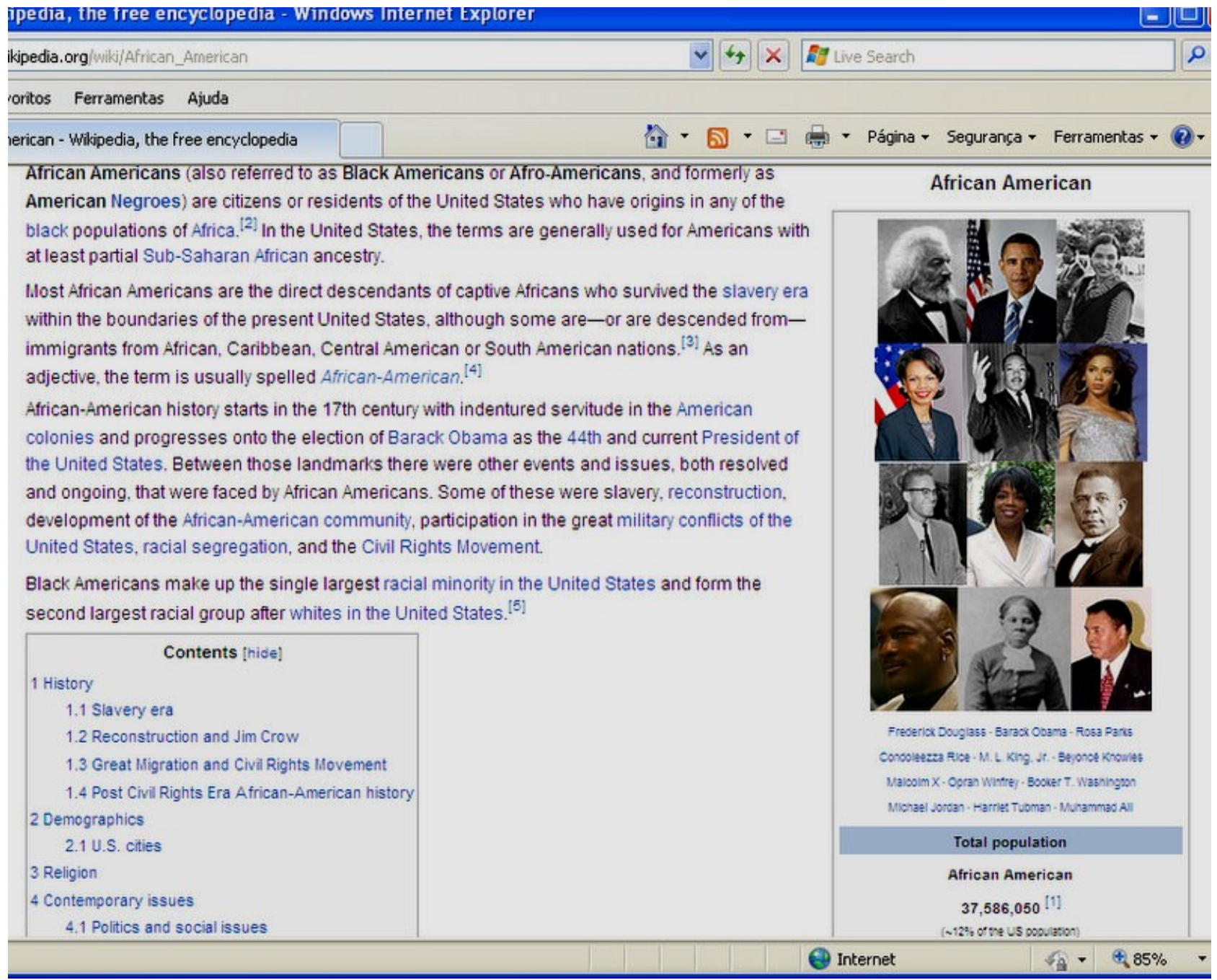

Acessado em 08/11/10: http://en.wikipedia.org/wiki/African_American
ATIVIDADE DE LEITURA CRÍTICA - RESPONDA EM PORTUGUÊS, SEMPRE QUE POSSÍVEL:
1- Você reconhece alguma das pessoas que aparecem nas fotos?Qual/ Quais?
2- De acordo com o texto, Barack Obama ocupa qual cargo?
3- Quantos antecessores ele teve?
4-Qual o assunto principal do texto?
5- O assunto do texto está relacionado com que possíveis áreas de estudo/matérias escolares?
6-Que tipo de pessoa pode ter escrito este texto?
7-Quem o leria?
8- Quais as regiôes de origem da população focalizada, de acordo com o texto? Cite todas.
9- De acordo com o texto, quando se inicia a história da população em destaque?
10- Em que região essa história se desenvolveu e onde essa população permanece até os dias de hoje?
11- Cite um evento ou situação problemática enfrentada pela população em destaque, de acordo com o texto.
12- De acordo com o texto, a região onde essa população vive é liderada por dois grandes grupos raciais. Quem
é o primeiro e quem é o segundo?
13- O segundo grupo racial mais populoso da região em destaque representa quantos por cento da população
total da região mencionada no texto?
14- No texto, a palavra BLACK está sendo usada com sentidos positivos ou negativos? Retire 2 exemplos, EM
INGLÊS, e justifique sua resposta.

Figura 6: Atividade de leitura crítica, compreendendo a subfase de detalhamento Ramos (2004). 
Uma interpretação da subfase de detalhamento, de uma perspectiva da Teoria da Relação com Saber (CHARLOT, 2000), indica que o ato do pesquisador de acrescentar novas questões e reformatar as atividades didáticas de leitura em LE inicialmente geradas pelos alunos tem conexão direta com o processo epistêmico de distanciação-regularização. Assim sendo, os alunos, ao verem as atividades que eles próprios criaram sendo tomadas como objeto de estudo pelos demais colegas, se encontraram localizados em uma dimensão de onde o aprendizado pôde ser visto como algo que construía aqueles seres, refletindo quem eles eram, seus papéis ativos como discentes, suas capacidades - sendo cada atividade didática de leitura em LE criada pelos discentes e reformatada pelo professor um instrumento contínuo e concreto para a consolidação dessa condição relacional, a qual está ligada ao processo epistêmico de distanciação-regulação.

\section{CONSIDERAÇÕES FINAIS}

Neste estudo, desenvolvido no âmbito de uma escola pública secundária nãoprofissionalizante, a partir do que preconizam os PCNs (1998) e a Matriz de Referência de Linguagens, Códigos e suas Tecnologias do ENEM (2009), relatei e discuti resultados de uma pesquisa-ação, que, no escopo de ensino de LFE (HUTCHINSON; WATERS, 1987; ROBINSON, 1991; DUDLEY-EVANS; ST. JOHN, 1998), considerou os gêneros textuais como unidade linguístico-discursiva central do currículo de um curso de leitura em LE, utilizando as TICs como recurso pedagógico.

Adotei o conceito de leitura conhecido como sociocognitivo (VAN DIJK, 2008; VEREZA, 2011), apoiando-me também na concepção de leitura oriunda do Modelo Interacional (MOITA LOPES, 1996).

O conceito de Gênero adotado foi o proveniente da Teoria de Gênero (EGGINS e SLADE, 1997 apud CARVALHO, 2011); (MARTIN; WHITE, 2005, p. 32 apud CARVALHO, 2011). A metodologia para a implementação do ensino de gêneros textuais foi a de Ramos (2004), contemplando suas etapas de planejamento e aplicação.

Neste sentido, no âmbito de um curso de dinâmicas e práticas, como sugeri aqui, e a partir das atividades de pesquisa e produção online, realizadas pelos alunos, aproveitei, primeiramente, seus conhecimentos acerca das TICs como produto. Nessa perspectiva, como vimos, o indivíduo "trabalha silenciosamente" para a Rede, no sentido de que, assim, ele não faz nada além de promovê-la. Como resultado, promove-se também o discurso tecnológico. Este, como instrumento de sua promoção, busca igualar práticas, gerando a "algoritmização" e maior controle sobre como e através de que mecanismos/equipamentos tais práticas podem se dar. Tendo isso em mente, busquei redirecionar esse conhecimento discente das TICs como produto. Procurei não só diagnosticar o nível inicial de leitura em LE desses alunos - através de dinâmicas e práticas que os levaram a produzir atividades didáticas de leitura em $L E$ - como também procurei projetar o desenvolvimento de suas habilidades de leitura em LE em três níveis. Meu objetivo, dentro de uma perspectiva sociointeracionista (VYGOTSKY, 1998), era promover, com base em princípios linguístico-pedagógicos, o letramento digital desses alunos, fazendo com que eles passassem, gradualmente, a ver as TICs como serviço. Dessa maneira, esses indivíduos passariam a usufruir da Rede - utilizando-a como meio de acesso ao desenvolvimento de conhecimentos - podendo vir a "desalgoritmizar" práticas sociais antes tidas como cristalizadas e socialmente hegemônicas (no sentido de Fairclough, 2001), uma vez que as necessidades de aprendizagens vão variar de acordo 
com gostos, necessidades e práticas (sociais) de cada um.

Tomei como argumento central o fato de, nas escolas públicas profissionalizantes, o ensino de LE com foco na habilidade leitora (mas não se restringindo a esta) vir sendo desenvolvido de forma mais estruturada e em atendimento a demandas mais claramente definidas - de acordo com as características e necessidades das comunidades discursivas (ASKEHAVE; SWALES, 2001) e das práticas sociais comuns às referidas comunidades, às quais o futuro aluno pretenderá pertencer, por conta de sua profissionalização. Por seu turno, os alunos das escolas públicas nãoprofissionalizantes, de uma perspectiva crítico-discursiva (FAIRCLOUGH, 2001) e crítico-reflexiva (FREIRE, 1988), parecem encontrar-se negligenciados e, de certa forma, excluídos, em decorrência de práticas não (re)interpretadas por parte dos docentes. Isso se dá, por exemplo, quando estes não atualizam essas práticas, de acordo com o que os PCNs (1998) e a Matriz de Referência de Linguagens, Códigos e suas Tecnologias do ENEM (2009) postulam. Tal postura, no mínimo, pode vir a prejudicar o aluno em futuros exames, por exemplo. Pode haver ainda aí, outro negligenciado: o professor; que na ausência do Estado, com carga horária estafante, no processo de rotinas não refletidas e na ação de tomar os livros didáticos como se fossem Bíblias Sagradas, negligencia não só sua prática como também aqueles que são diretamente afetados por aquela.

Por fim, discuti, em seguida, como, apesar de todas as instâncias dos problemas apontados no parágrafo anterior, o fazer pedagógico do professor da escola não-profisionalizante pode se mostrar (re)interpretável em termos de: abordagem linguística, habilidades e competências para o ensino-aprendizagem de leitura em LE; práticas docente, discente e de linguagem, tendo em vista uma posição crítico-reflexiva (FREIRE, 1988), linguístico-aplicada e crítica (PENNYCOOK, 2010) e crítico-discursiva (FAIRCLOUGH, 2001) desse processo. Assim, a possível (re)interpretação do referido processo se coloca como um poderoso instrumento de ação social, podendo estar a serviço de minimizar disparidades entre alunos de escolas secundárias nãoprofissionalizantes e alunos de outras instituições. Desse modo, através da concepção de ensinoaprendizagem de leitura em LE discutida aqui, busquei fazer com que os alunos, antes negligenciados, tivessem acesso a informações de diversas naturezas, a diversas comunidades discursivas; desempenhando diversas práticas (sociais).

\section{REFERÊNCIAS}

ASKEHAVE, I.; SWALES, J. Genre identification and communicative purpose: a problem and a possible solution. Applied Linguistics. 22.2, 2001. p. 195-212.

BARTON, D; HAMILTON, M. Local Literacies: Reading and writing in one community. London, Routledge, 1998.

BRASIL. Parâmetros Curriculares Nacionais: terceiro e quarto ciclos do Ensino Fundamental: Língua Estrangeira. Secretaria de educação fundamental, Brasília: MEC/SEF, 1998.

BRASIL. Matriz de competências para o Enem 2009. Ministério da Educação. Instituto Nacional de Estudos e Pesquisas Educacionais Anísio Teixeira. Brasília, 2009.

CARVALHO, G. A teoria traduzida em prática: atividades de leitura baseadas nos conceitos de 
contexto de cultura e contexto de situação. In: TAVARES, K.; BESCHER, S.; FRANCO. C.; (Org.) Ensino de Leitura: fundamentos, práticas e reflexões para professores da era digital. Rio de Janeiro: Faculdade de Letras da UFRJ, 2011. p. 49-63.

CELANI, M. A. A. Parâmetros Nacionais - LE: focalizando a questão dos conteúdos e dos temas transversais. In: $13^{\circ}$ SEMINÁRIO NACIONAL DE ENSINO DE INGLÊS INSTRUMENTAL DO BRASIL. Rio de Janeiro: Uerj, 1999.

CHAMBERLAIN, D.; BAUMGARDNER, R.J. (Ed.). ESP in the classroom: practice and evaluation, ELT document 128, Modern English publication in association with The British Council, 1988.

CHARLOT, B. Da relação com o saber: elementos para uma teoria. Porto Alegre: Artmed, 2000.

CHARTIER, R. História da leitura no mundo ocidental. São Paulo: Ática, 1998.

CHARTIER, R. Cultura escrita, literatura e história. Porto Alegre: Artmed, 2001.

COLOMER, T.; A. CAMPS. Enseñar a leer, enseñar a comprender, Madrid: Celeste, 2000.

DROGA, L.; HUMPHREY, S. Getting Started with Functional Grammar. Marckville, Au.: Target Texts. 2002.

DUDLEY-EVANS, T.; ST. JOHN, M. J. Developments in English for specific purposes. Cambridge. CUP, 1998.

EGGINS, S. An Introduction to Systemic Functional Linguistics. London: Continuum International Publishing Group Ltd, 1994.

EGGINS, S.; SLADE, D. Analysing Casual Conversation. London: Cassel, 1997.

FAIRCLOUGH, N. Discurso e mudança social. Brasília: UnB, 2001.

FOUCAMBERT, J. A leitura em questão. Porto Alegre: Artes Médicas, 1984.

FREIRE, P. A importância do ato de ler: em três artigos que se completam. 22. ed. São Paulo: Cortez, 1988.

FREIRE, P. A importância do ato de ler. São Paulo: Cortez, 1994.

HALLIDAY, M.A.K. Introduction to functional grammar. 2. ed. Edward Arnold,1985.

HALLIDAY, M.A.K.; HASAN, R. Language, Context and Text: Aspects of Language in a Socialsemiotic perspective. Oxford: Oxford University Press, 1985.

HUTCHINSON, T.; WATERS A. English for specific purposes: a learning-centered approach. Cambridge, CUP, 1987. 
ILLICH, I. Um apelo à pesquisa em cultura escrita leiga. In: OLSON, David. R.; TORRANCE, Nancy. Cultura escrita e Oralidade. São Paulo: Ática, 1995. p. 35-54.

KLEIMAN, A. Oficina de leitura. Campinas: Pontes/Unicamp, 1993.

KLEIMAN, A. (Org.). Os significados do letramento. Campinas: Mercado das Letras, 1995.

MANGUEL, A. Uma história da leitura. Tradução Pedro Maia Soares. São Paulo: Companhia das Letras, 1997.

MARTIN, J.R.; WHITE, P. R. R. The Language of Evaluation. New York: Palgrave Macmillan, 2005.

MOITA LOPES, L. P. Oficina de linguística aplicada: a natureza social e educacional dos processos de ensino/aprendizagem em línguas. São Paulo: Mercado das Letras, 1996.

OLSON, D. R. O mundo no papel: as implicações conceituais e cognitivas da leitura e da escrita. São Paulo: Ática, 1997.

OLSON, David. R.; TORRANCE, Nancy. Cultura escrita e Oralidade. São Paulo: Ática, 1995.

PENNYCOOK, A. Critical and alternative directions in applied linguistics. Australian Review of Applied Linguistics. 33 (2), p. 16.1-16.16. DOI: 10.2104/aral1016. 2010.

RAMOS, R. C. G. Gêneros textuais: uma proposta de aplicação em cursos de Inglês para fins específicos. The ESPecialist, v. 25, n. 2, 2004. p. 107-129.

ROBINSON, P. C. ESP Today: a practitioner’s guide. Englewood Cliffs: Prentice Hall, 1991.

SERRANI, Silvana (Org.). Letramento, discurso e trabalho docente. Vinhedo: Horizonte, 2010.

SILVA, S. B. B. da. O texto literário na formação de leitores jovens e adultos. In: SERRANI, Silvana (Org.). Letramento, discurso e trabalho docente. Vinhedo: Horizonte, 2010. p. 56-70.

SILVA, C. E. da. O processo de compreensão na leitura em língua estrangeira: relato de uma experiência com alunos do $2^{\circ}$ grau. São Paulo: Humanitas, 2001.

SOTO, Ucy et. al. Novas tecnologias em sala de aula (re)construindo conceitos e práticas. São Carlos: Claraluz, 2009.

SOUZA JÚNIOR, J. Inglês para leitura: etapas do curso. Monografia de conclusão de curso (Pósgraduação lato sensu em linguística aplicada em inglês como língua estrangeira) Uerj/RJ, Rio de Janeiro, 2009.

STREVENS, P. The learner and the teacher of ESP. In: CHAMBERLAIN, D.; BAUMGARDNER, R.J. (Ed.). ESP in the classroom: practice and evaluation, ELT document 128, Modern English publication in association with The British Council, 1988. p. 39-44. 
TAVARES, K. ; BESCHER, S.; FRANCO. C.; (Org.). Ensino de Leitura: fundamentos, práticas e reflexões para professores da era digital. Rio de Janeiro: Faculdade de Letras da UFRJ, 2011.

VAN DIJK, T.A. Discourse and Context. A sociocognitive approach. Cambridge: CUP, 2008.

VEREZA, S. C. Uma breve trajetória das abordagens pedagógicas da leitura: a alternativa sociocognitivista. In: TAVARES, K.; BESCHER, S.; FRANCO. C.; (Org.). Ensino de Leitura: fundamentos, práticas e reflexões para professores da era digital. Rio de Janeiro: Faculdade de Letras da UFRJ, 2011. p. 13-25.

VERGNANO-JUNGER, C. de S. Leitura na tela: reconstruindo uma prática antiga. In: SOTO, Ucy et. al. Novas tecnologias em sala de aula (re)construindo conceitos e práticas. São Carlos: Claraluz, 2009. p. 25-34.

VYGOTSKY, L. S. A Formação Social da Mente: o Desenvolvimento dos Processos Psicológicos Superiores. São Paulo: Martins Fontes, 1998.

WOLTON, D. As novas tecnologias, o indivíduo e a sociedade. In: WOLTON, D. Internet, $e$ depois? Uma teoria crítica das novas mídias. Porto Alegre: Sulina, 2007. p. 84-118.

WOLTON, D. Internet, e depois? Uma teoria crítica das novas mídias. Porto Alegre: Sulina, 2007. 
i Trabalho de conclusão de curso de pós-graduação lato sensu, apresentado ao ILE/Uerj, no mesmo ano, desenvolvido sob a orientação da professora doutora Rosângela Ávila Dantas (Uerj). Acrescento que o presente artigo foi concebido no âmbito da disciplina de Linguística Aplicada (LET 06749), oferecida pelo Mestrado em Linguística (Uerj), mais especificamente no curso denominado: “ Leitura na era digital: uma revisão do estado da arte”, ministrado em 2013.1, pela professora doutora Cristina de Souza Vergnano-Junger (Uerj).

ii Neste trabalho, utilizamos o termo "texto autêntico" em consonância com o que os PCNs (BRASIL, 1998, p. 72) sugerem.

iii O Governo Federal, por meio do Ministério da Educação, tem buscado promover a inclusão digital nas escolas públicas de todo o país. Assim, foi criado o Programa Nacional de Tecnologia Educacional - PROINFO, criado pela portaria $n^{\circ}$ 522/MEC, de 9 de abril de 1997. Considerando esse fato, ratifico uma visão da aplicabilidade e do uso crítico-pedagógico das tecnologias nas escolas públicas.

iv Inglês Geral (IG), como utilizado em Souza Júnior (2009), faz referência à modalidade de ensino de Inglês na qual os objetivos de um curso são pré-definidos, não sendo tais objetivos ligados a um propósito específico, portanto.

v Sugiro ver Moita Lopes (1996).

vi Disponível

em:

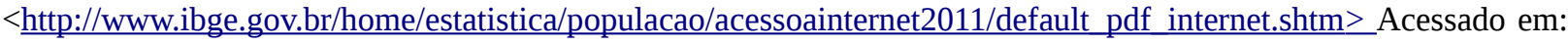
05 ago 2013.

vii Sugiro ver Charlot (2000).

viii Para maior detalhamento, sugiro ver Ramos (2004). 